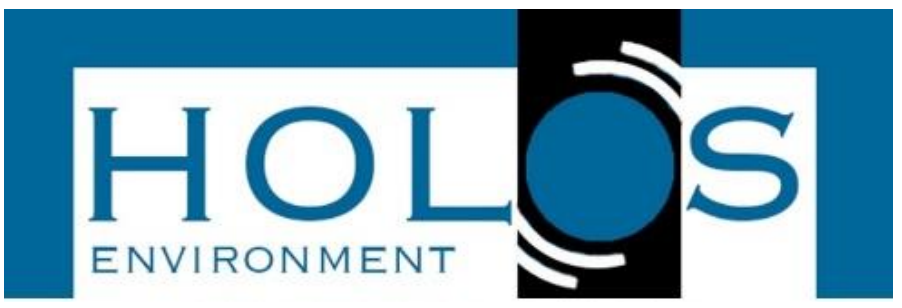

\title{
EFEITOS DA DRENAGEM ÁCIDA DE MINA SOBRE A QUALIDADE DAS ÁGUAS SUBTERRÂNEAS: PRECEITOS LEGAIS E TÉCNICOS
}

\section{EFECTS OF ACID MINE DRAINAGE ON GROUNDWATER QUALITY: LEGAL AND TECHNICAL ASPECTS}

\author{
Juliana Aparecida Galhardi ${ }^{1}$, Bruna Camargo Soldera²,
}

Artigo recebido em: 06/10/2017 e aceito para publicação em: 23/04/2018.

DOI: http://dx.doi.org/10.14295/holos.v18i1.12247

Resumo: Atividades de mineração podem causar degradação ambiental em grandes extensões, comprometendo solos, águas superficiais e subterrâneas, atmosfera e a biota. A exploração mineral tem como consequência a exposição de grandes quantidades de sulfetos a processos de intemperismo que geram ambientes ácidos em consequência da produção de drenagem ácida de mina (DAM), promovendo a solubilização de metais e o transporte destes para os fluxos de águas naturais. Entretanto, as variações hidroquímicas das águas subterrâneas em áreas de mineração e os efeitos da DAM sobre os aquíferos foram ainda pouco investigados no Brasil. Este trabalho visou identificar as principais normas legais que gerem a qualidade dos recursos hídricos subterrâneos no Brasil, de forma a integrar aspectos ambientais, técnicos e legais concernentes aos impactos da DAM sobre as águas subterrâneas, possibilitando, dessa forma, identificar os fatores mais urgentes a serem desenvolvidos com o intuito de proteger efetivamente tais recursos. Entre tais fatores, a definição de critérios de lançamento de efluentes sobre os solos e águas é essencial, inclusive para projetar-se um sistema de coleta, tratamento e disposição final de resíduos em áreas de mineração que atendam a preceitos básicos de qualidade ambiental. Para isso, uma avaliação criteriosa sobre os processos ambientais e geoquímicos operantes no meio é essencial durante o planejamento prémineração, operatório e pós-operação. Desta forma, os problemas concernentes aos efluentes ácidos gerados, que podem comprometer profundamente os ecossistemas, não serão resolvidos em curto prazo por meio de uma intervenção pontual e desarticulada com parâmetros legais e ambientais.

Palavras-chave: Drenagem ácida de mina. Contaminação ambiental. Águas subterrâneas. Hidrogeologia.

Abstract: Mining activities can increase environmental problems, compromising soils, surface water, groundwater, atmosphere and biota. Mineral exploitation can result in the exposure of large amounts of sulfides to weathering processes that generate acid effluents due to the formation of acid mine drainage (AMD), promoting solubilisation and transporting of metals to natural waters. However, the hydrochemical variations of groundwater in mining areas and the effects of AMD on aquifers were still poorly investigated. This work aimed to identify the main legal aspects for managing the quality of water resources in Brazil, specifically the groundwaters, in order to integrate environmental, technical and legal aspects concerning the impacts of AMD on groundwaters, thus allowing us to identify the factors to be developed in order to effectively protect these resources. The definition of criteria for the release of acid effluents into soils and water resources is essential to project a system for the collection, treatment and final disposal of wastes in mining areas complying with basic parameters of environmental quality. Therefore, a careful evaluation of environmental and geochemical processes is essential during the pre-mining, mining and post-operation planning. Thus, the problems related

\footnotetext{
${ }_{1}^{1}$ Universidade de Montreal, Canada. Email: (julianagalhardi@yahoo.com.br)

2 Universidade Estadual Paulista "Júlio de Mesquita Filho (UNESP) - Instituto de Geociências e Ciências Exatas, São Paulo, SP. Email: (brusoldera@hotmail.com)
} 
to the acid effluents, which compromises the ecosystems in deep dimensions, will not be solved in short time through punctual intervention disjointed with legal and environmental aspects.

Keywords: Acid mine drainage. Environmental contamination. Groundwater. Hydrogeology.

\section{INTRODUÇÃO}

Atividades de mineração podem contribuir para a lixiviação de minerais das rochas para o ambiente em seu entorno e acarretar severos danos ambientais (USEPA, 1995; BAIK et al., 2003; FLUES et al., 2003; FUNGARO e IZIDORO, 2006). Os principais problemas ambientais durante as etapas de lavra e beneficiamento de minérios decorrem da disposição de resíduos sólidos que dão origem à drenagem ácida de mina (DAM).

A DAM surge em decorrência da oxidação de sulfetos minerais quando expostos ao oxigênio e água, acarretando uma sequência de reações que podem resultar na produção de espécies que promovem redução de pH e na liberação de vários metais para o meio, como ferro ( $\mathrm{Fe}$ ), alumínio ( $\mathrm{Al}$ ) e manganês $(\mathrm{Mn})$. Além disso, pode ocorrer a lixiviação de elementos tóxicos e a dispersão de contaminantes para o ambiente (FLUES e FORNARO, 2003) e também podem ser evidenciados impactos radiológicos (USEPA, 1995). Estes processos podem ser acelerados por atividades mineiras envolvendo escavação de rochas contendo minerais de sulfetos devido ao aumento da exposição destes ao ar, água e microrganismos. Uma vez liberados, os elementos tóxicos podem atingir solos e águas naturais, causando danos severos aos organismos vivos.

Apesar da DAM ser identificada como um problema iminente já nos anos 70 , os processos de remediação disponíveis, que são ineficientes, somados a conflitos entre governo, empresas e organizações não-governamentais, resultaram em recursos e maneiras ineficazes para lidar efetivamente com seu controle (SIMATE e NDLOVU, 2014). Somado a isto, poucos estudos analisaram as variações hidroquímicas das águas subterrâneas em áreas de mineração no Brasil, os efeitos da DAM sobre os aquíferos e formas efetivas para o controle ambiental.

Este trabalho objetiva evidenciar as principais reações químicas e fatores ambientais que dão origem aos efluentes ácidos oriundos de áreas de mineração, salientar as principais influências destes sobre os recursos hídricos subterrâneos e as políticas para gestão ambiental que abordam esta questão. Foram pesquisadas as principais normas legais que gerem a qualidade dos recursos hídricos no Brasil e as que especificamente 
pautam sobre as águas subterrâneas. Os principais impactos da DAM sobre as águas subterrâneas foram brevemente descritos como forma de elucidar as atividades de mineração que dão origem a estes efluentes ácidos e que podem comprometer a qualidade dos aquíferos. Dessa forma, integrando-se aspectos ambientais, técnicos e legais, este estudo procura identificar os fatores mais urgentes a serem desenvolvidos com o intuito de proteger efetivamente os recursos hídricos, em especial as águas subterrâneas.

\section{FORMAÇÃO DE DRENAGEM ÁCIDA EM AMBIENTES DE MINERAÇÃO}

A exploração de certos minerais está associada aos problemas e danos ambientais que a drenagem ácida pode causar. Caracterizada por apresentar baixo $\mathrm{pH}$ e altas concentrações de elementos tóxicos, a DAM pode comprometer severamente e em longo prazo a qualidade das águas superficiais e subterrâneas, bem como os solos (AKCIL e KOLDAS, 2006).

Os principais minerais que podem originar DAM são a pirita $\left(\mathrm{FeS}_{2}\right)$ e a marcassita ( $\left.\mathrm{FeS}_{2}\right)$, mas a pirrotita $(\mathrm{FeS})$, arsenopirita (FeAsS), calcopirita $\left(\mathrm{CuFeS}_{2}\right)$ e outros minerais de sulfeto contendo ferro $(\mathrm{Fe})$, cobre $(\mathrm{Cu})$, arsênio $(\mathrm{As})$, antimônio $(\mathrm{Sb})$, bismuto $(\mathrm{Bi})$, selênio (Se) e molibdênio (Mo) podem também produzir soluções ácidas (BERGHORN e HUNZEKER, 2001). A pirita é o principal responsável pela geração de DAM (Equação 1) e a reação global pode ser escrita como:

$$
4 \mathrm{FeS}_{2}+15 \mathrm{O}_{2}+14 \mathrm{H}_{2} \mathrm{O} \rightarrow 4 \mathrm{Fe}(\mathrm{OH})_{3} \downarrow+8 \mathrm{H}_{2} \mathrm{SO}_{4}
$$

Soluções de DAM comumente apresentam pH abaixo de 3 e agem como lixiviantes efetivos de metais em ambiente de mineração. As reações químicas que resultam na formação de efluentes ácidos podem ser representadas pela sequência de reações (ALHASHIMl et al., 1996):

$$
\begin{gathered}
\mathrm{FeS}_{2}+7 / 2 \mathrm{O}_{2}+\mathrm{H}_{2} \mathrm{O} \rightarrow \mathrm{Fe}^{2+}+2 \mathrm{SO}_{4}^{2-}+2 \mathrm{H}^{+} \\
\mathrm{Fe}^{2+}+5 / 2 \mathrm{H}_{2} \mathrm{O}+1 / 2 \mathrm{O}_{2} \rightarrow \mathrm{Fe}(\mathrm{OH})_{3} \downarrow+2 \mathrm{H}^{+} \\
\mathrm{Fe}^{2+}+1 / 4 \mathrm{O}_{2}+\mathrm{H}^{+} \rightarrow \mathrm{Fe}^{3+}+1 / 2 \mathrm{H}_{2} \mathrm{O} \\
\mathrm{FeS}_{2}+14 \mathrm{Fe}^{3+}+8 \mathrm{H}_{2} \mathrm{O} \rightarrow 15 \mathrm{Fe}^{2+}+2 \mathrm{SO}_{4}^{2-}+16 \mathrm{H}^{+}
\end{gathered}
$$


A primeira reação (Equação 2) inclui a oxidação da pirita sólida pelo oxigênio. $O$ enxofre é oxidado a sulfato $\left(\mathrm{SO}_{4}{ }^{2-}\right)$ e o ferro ferroso $\left(\mathrm{Fe}^{2+}\right)$ é liberado. Dois moles de acidez $\left(\mathrm{H}^{+}\right)$são gerados para cada mol de pirita oxidada. Os metais são liberados durante as fases iniciais de oxidação da pirita. Estes podem combinar-se com materiais alcalinos, presentes na rocha hospedeira ou frequentemente adicionados aos rejeitos, formando precipitados metálicos (Equação 3). Com o avançar das reações (Equação 4), com o decréscimo do pH, os precipitados podem retornar para a solução quando a alcalinidade disponível se esgota. Em valores de $\mathrm{pH}$ próximos ou inferiores a 3 , a hidrólise praticamente não ocorre. $\mathrm{A}$ concentração de $\mathrm{Fe}^{3+}$ aumenta no meio, servindo de agente oxidante para a pirita (Equação 5). Assim, nesta etapa, o ferro férrico $\left(\mathrm{Fe}^{3+}\right)$, que foi gerado anteriormente, é o agente oxidante para pirita, sendo uma etapa cíclica e autorregulada que ocorre muito rapidamente até que o ferro férrico ou a pirita se tornem esgotados. O produto final é o ferro na forma solúvel $\left(\mathrm{Fe}^{2+}\right)$ ou sólida $\left(\mathrm{Fe}(\mathrm{OH})_{3}\right)$.

Em condições de baixo $\mathrm{pH}$ a solubilidade do ferro férrico aumenta, assim como sua disponibilidade como agente oxidante. A oxidação do íon ferroso é muitas vezes considerada o passo limitante para a formação da DAM (AL-HASHIMI et al., 1996) e o processo pode aumentar várias ordens de grandeza devido à atividade bacteriana. Duas espécies de bactérias envolvidas nesse processo são a Acidithiobacilus thiooxidans e Acidithiobacilus ferroxidans (FRANCIS, 1990; SILVA et al., 2011). Na ausência de bactérias, $\mathrm{Fe}^{3+}$ não é produzido a um ritmo significativo $(\mathrm{pH}<4)$ ou é tão insolúvel que sua forma dissolvida é relativamente inexpressiva como um oxidante de pirita $(\mathrm{pH}>4)$. Após a oxidação do ferro, este tende a sofrer hidrólise em solução de acordo com as reações descritas pelas Equações 6-9:

$$
\begin{gathered}
2 \mathrm{Fe}^{3+}+2 \mathrm{H}_{2} \mathrm{O} \rightarrow 2 \mathrm{FeOH}^{2+} \\
2 \mathrm{FeOH}^{2+}+\mathrm{H}_{2} \mathrm{O} \rightarrow 2 \mathrm{Fe}(\mathrm{OH})_{2}^{+}+2 \mathrm{H}^{+} \\
2 \mathrm{Fe}(\mathrm{OH})_{2}+2 \mathrm{H}_{2} \mathrm{O} \rightarrow 2 \mathrm{Fe}(\mathrm{OH})_{3}+2 \mathrm{H}^{+} \\
2 \mathrm{Fe}\left(\mathrm{SO}_{4}\right)_{3}+6 \mathrm{H}_{2} \mathrm{O} \rightarrow 2 \mathrm{Fe}(\mathrm{OH})_{3}+3 \mathrm{H}_{2} \mathrm{SO}_{4}
\end{gathered}
$$

Estas reações, descritas por Al-Hashimi et al. (1996), levam a um aumento da formação de ácido no ambiente. Dessa forma, a oxidação da pirita e a hidrólise de íons 
férricos são os principais mecanismos de geração de DAM.

Além das reações que tornam o meio ácido, pode ocorrer a dissolução de minerais carbonatados que consomem $\mathrm{H}^{+}$e neutralizam a acidez. Se a água que flui em contato com a pirita for alcalina, as reações descritas anteriormente podem ser inibidas de modo que pouca ou nenhuma DAM é produzida. Por outro lado, uma vez formada, a interação da DAM com materiais alcalinos pode, ao neutralizar a acidez, promover a remoção de $\mathrm{Fe}, \mathrm{Al}$ e outros metais. Assim, águas com elevado teor de sulfato e baixo teor de ferro pode ser indicativo de DAM gerada previamente e controlada com o passar do tempo (BERGHORN e HUNZEKER, 2001).

Calcita $\left(\mathrm{CaCO}_{3}\right)$ e dolomita $\left(\mathrm{CaMg}\left(\mathrm{CO}_{3}\right)_{2}\right)$ são os principais minerais que fornecem alcalinidade nas águas superficiais e subterrâneas. Nas minas em que há adição de cal ( $\mathrm{CaO})$ nos resíduos durante seu acondicionamento em pilhas, as reações de neutralização da solução ácida podem ser descritas pelas Equações 10-12 (MELLO et al., 2014):

$$
\begin{aligned}
& \mathrm{Ca}(\mathrm{OH})_{2(\mathrm{~s})}+\mathrm{H}_{2} \mathrm{SO}_{4(\mathrm{aq})} \rightarrow \mathrm{Ca}^{2+}{ }_{(\mathrm{aq})}+\mathrm{SO}_{4}{ }^{2-}{ }_{(\mathrm{aq})}+2 \mathrm{H}_{2} \mathrm{O}_{(\mathrm{aq})} \\
& 2 \mathrm{FeSO}_{4(\mathrm{~s})}+2 \mathrm{Ca}(\mathrm{OH})_{2(\mathrm{~s})} \rightarrow 2 \mathrm{CaSO}_{4(\mathrm{~s})}+2 \mathrm{Fe}(\mathrm{OH})_{2(\mathrm{~s})} \\
& 2 \mathrm{Fe}(\mathrm{OH})_{2(\mathrm{~s})}+\mathrm{H}_{2} \mathrm{O}_{(\mathrm{aq})}+1 / 2 \mathrm{O}_{2(\mathrm{~g})} \rightarrow 2 \mathrm{Fe}(\mathrm{OH})_{3(\mathrm{~s})}
\end{aligned}
$$

As reações de oxidação da pirita são ilimitadas em condições atmosféricas, ao passo que as reações produtoras de alcalinidade são limitadas pela solubilidade dos carbonatos. Outros minerais importantes para a atenuação da contaminação ambiental associada com a DAM são a jarosita $\left(\mathrm{K}_{2} \mathrm{Fe}_{6}(\mathrm{OH})_{12}\left(\mathrm{SO}_{4}\right)_{4}\right)$ e goethita $(\mathrm{FeO}(\mathrm{OH}))$, pois elementos tais como chumbo $(\mathrm{Pb})$ e crômio $(\mathrm{Cr})$ podem ser assimilados em suas estruturas (SIMONA et al., 2004; SILVA et al., 2013).

\section{EFEITOS DA DAM EM SUBSUPERFÍCIE}

A Figura 1 exibe alguns dos principais efeitos da DAM no ambiente após seu contato com os solos e as águas subterrâneas. A importância de cada fator que leva à poluição por DAM varia dentro e entre os sistemas afetados.

Os efeitos químicos e físicos sobre os aquíferos podem levar a danos irreparáveis nos ecossistemas, especialmente ao ambiente subsuperficial. Não obstante, os impactos 
da DAM para as águas subterrâneas foram menos investigados. Sabe-se, contudo, que a infiltração de efluentes ácidos é possível e frequente, o que modifica drasticamente a qualidade das águas subterrâneas em áreas de mineração, tornando-as frequentemente impróprias para o consumo humano (GALHARDI e BONOTTO, 2016).

Figura 1 - Principais efeitos da DAM sobre o meio subsuperficial

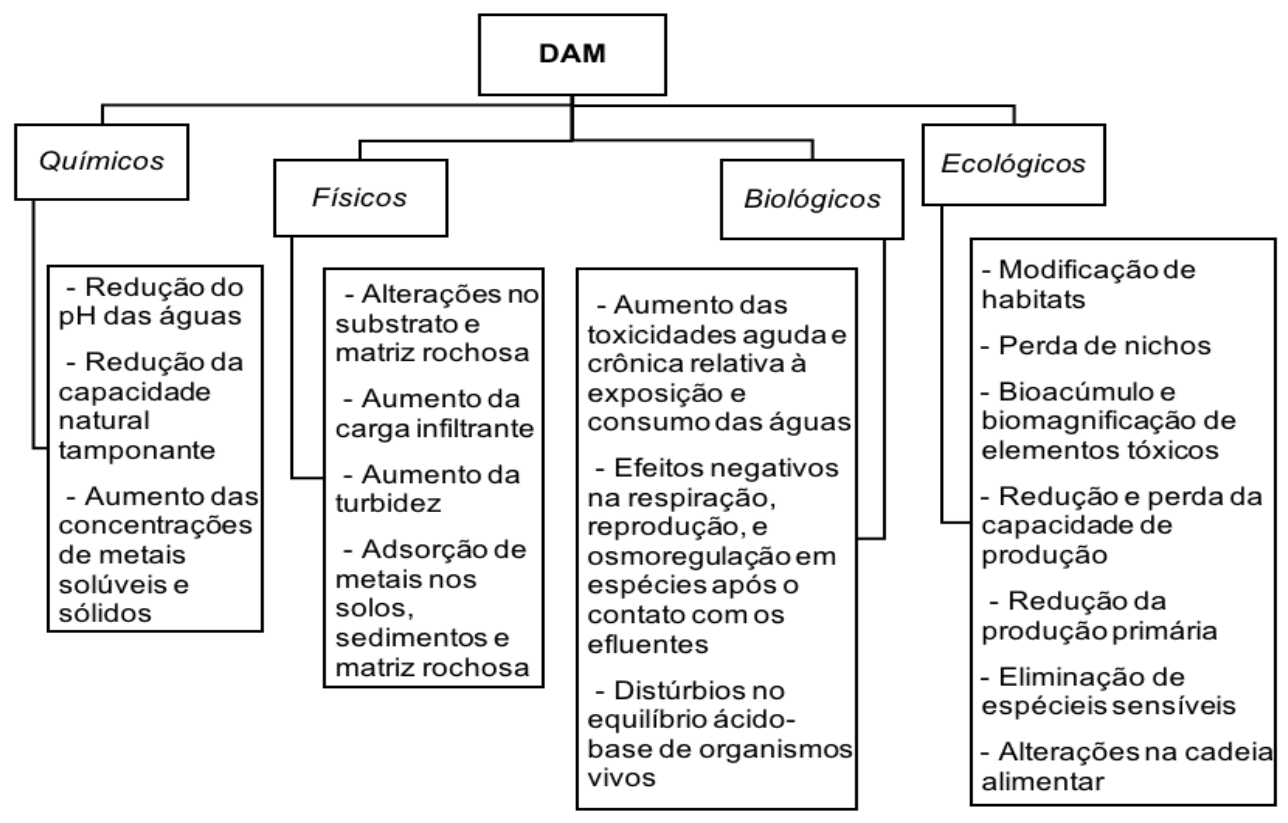

Fonte: Modificado de Gray (1997)

Mineração a céu aberto pode resultar em escavações profundas em depósitos de minério no subsolo e geralmente envolve a criação de uma cava que se estende abaixo do nível freático. As águas subterrâneas são bombeadas para fora da cava para permitir que a mineração ocorra. Uma vez encerradas as atividades e o bombeamento, uma lagoa pode formar-se, preenchendo a estrutura. O mesmo ocorre no caso de mineração subterrânea, em que galerias no subsolo por vezes atingem o nível freático e podem ser preenchidas por água, uma vez cessada as atividades de extração mineral e o bombeamento da água.

Os impactos destes reservatórios, das barragens de rejeitos e dos resíduos de mineração sobre a qualidade das águas subterrâneas podem ser graves, uma vez que pode ocorrer a lixiviação de elementos tóxicos e seu transporte para o ambiente subsuperficial. No caso das lagoas superficiais, este problema faz-se mais drástico especialmente se as bases destas instalações não forem impermeabilizadas adequadamente. A disposição de resíduos e rejeitos originados durante as etapas de lavra e beneficiamento mineral, 
contudo, é a principal fonte de impactos ambientais em ambiente de mineração (FUNGARO e IZIDORO, 2006), pois podem dar origem à DAM.

Os rejeitos dispostos em pilhas podem ser divididos em três grandes zonas com base no grau de intemperismo químico (Figura 2). Nos primeiros centímetros (<50 cm), 0 intemperismo é extremamente ativo para a maioria dos processos biogeoquímicos que se processam em larga escala na interface água-rocha-ar. Este horizonte é seguido por uma zona intermediária subjacente caracterizada pela lixiviação química. Nesta camada, os rejeitos não são diretamente expostos à atmosfera, porém recebem algum oxigênio advindo da percolação da água de superfície ou nível freático flutuante. O horizonte mais inferior permanece saturado por água durante grande parte do ano, mantendo uma relativa uniformidade nas condições físico-químicas.

A hidrogeoquímica da DAM pode ser significativamente influenciada por flutuações sazonais. Redissolução e precipitação de sais evaporíticos durante períodos de seca e chuva, dissolução de rochas e minerais e flutuações pluviométricas de longo prazo podem controlar a variabilidade da vazão da DAM (KIM e KIM, 2004). Variações sazonais na poluição por DAM revelam uma clara correlação entre períodos de seca e chuva com concentrações de metais nos efluentes e águas com as quais entram em contato (GALHARDI e BONOTTO, 2015). Deste modo, podem ser esperadas consequências graves das mudanças climáticas globais sobre os efeitos da DAM nos ambientes, os quais são difíceis de prever (NORDSTROM et al., 2000).

Figura 2 - Diagrama ilustrando o intemperismo de minerais de sulfeto, formação de DAM, acidificação do meio, lixiviação de metais $\left(\mathrm{M}^{+}\right)$e transporte destes até as águas subterrâneas.

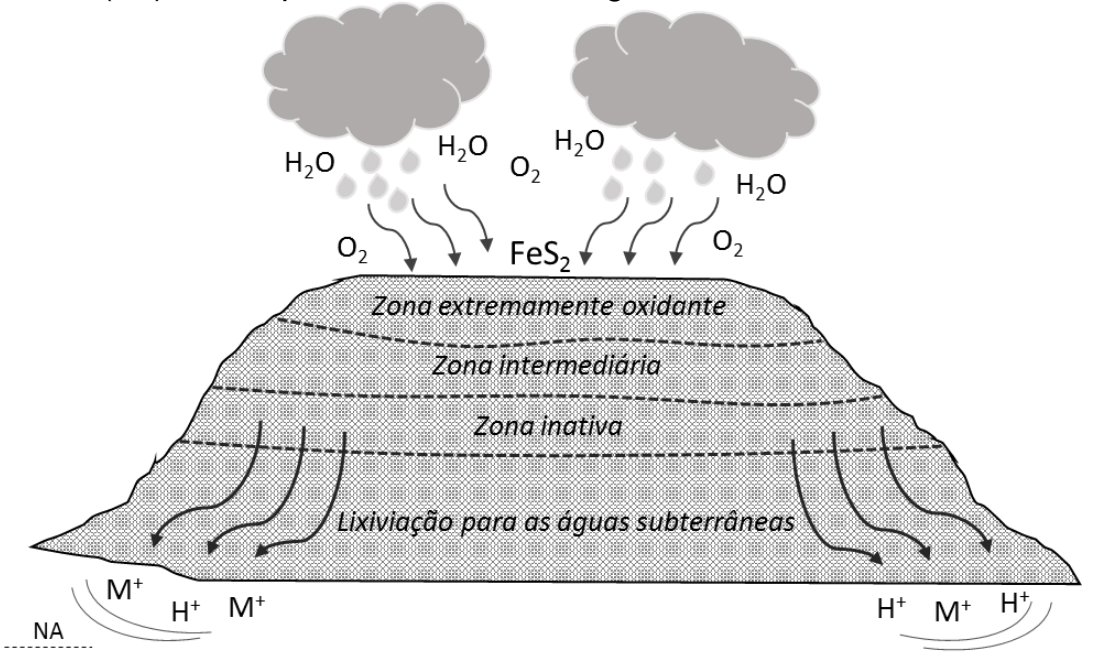

Fonte: Modificado de Paikaray (2015) 
Apenas alguns estudos analisaram as variações hidroquímicas das águas subterrâneas em áreas de mineração de sulfetos metálicos (NORDSTROM et al., 2000). A maior parte das pesquisas sobre efeitos da DAM em águas subterrâneas ocorreu em áreas de mineração de carvão (JARVIS et al., 2006; YOUNGER, 2004; GALHARDI e BONOTTO, 2015). Nestas áreas, a longevidade da acidez nas águas devido à dissolução dos sulfetos presentes nos corpos das galerias subterrâneas pode se estender ao longo de centenas ou milhares de anos (YOUNGER, 1997; YOUNGER, 2004).

\section{ASPECTOS LEGAIS SOBRE A CONTAMINAÇÃO DE ÁGUAS POR DAM}

Aspectos nacionais sobre atividades mineradoras foram regulamentados pelo Decreto no 227 de 1967 (BRASIL, 1967), que inicialmente dispôs sobre o aproveitamento dos recursos minerais. A Lei o 6.938 de 1981 (BRASIL, 1981) dispõe sobre a Política Nacional de Meio Ambiente e foi regulamentada pelo Decreto Lei oㅜ 97.632 de 1989 (BRASIL, 1989), que instituiu o Plano de Recuperação de Áreas Degradadas (PRAD), sendo considerados marcos para a conservação ambiental no país. A Lei o 7.805 de 1989 (BRASIL, 1989) responsabiliza as empresas pela recuperação dos danos causados ao ambiente devido atividades de mineração. Deste modo, os proprietários de concessões de mineração devem promover a reabilitação das áreas após o fechamento das minas, em concordância com o PRAD.

O Departamento Nacional de Pesquisa Mineral (DNPM) publicou uma série de Normas Regulamentares de Mineração (NRM) por meio de sua Portaria o 237 de 2001 (BRASIL, 2001), alterada pela Portaria № 12 de 2002 (BRASIL, 2002). Algumas normas que se destacam são a NRM 19 (sobre disposição de estéril, rejeitos e outros produtos), NRM 20 (sobre a suspensão, fechamento de mina e retomada das operações minerais) e a NRM 21 (a qual dispõe sobre a reabilitação de áreas pesquisadas, mineradas e impactadas), as quais o fechamento da mina e a suspensão das operações de lavra devem obedecer.

A empresa deve comprovar desde o início capacidade técnica e estrutural para implantar, operar e encerrar a mina, em virtude de obter as licenças requeridas pelos órgãos ambientais, descritos na Resolução CONAMA no 237 de 1997 (BRASIL, 1997a). O Plano de Fechamento de Mina é outro instrumento para garantir a reabilitação das áreas 
exploradas por atividades mineiras e, assim como o PRAD, deve atender exigências legais, considerar aspectos ambientais, econômicos e sociais (LIMA et al., 2006), buscando garantir à sociedade a recuperação dos ecossistemas afetados.

Concernente a qualidade das águas, alguns padrões foram estabelecidos no Brasil com vistas à potabilidade e preservação dos recursos hídricos, como descritos e destacados por Soldera (2017). Destaca-se a Lei Federal oㅜ 9.433, de 1997, que tem como objetivo a gestão sustentável e integrada dos recursos hídricos superficiais e subterrâneos (BRASIL, 1997b). A Resolução CONAMA o 357 de 2005 classifica e enquadra os corpos d'água superficiais e estabelece condições e padrões de lançamento de efluentes (BRASIL, 2005), a qual foi revisada em 2011 por meio da publicação da Resolução CONAMA no 430, a qual complementa e altera as condições e padrões de lançamento de efluentes (Brasil, 2005b). A Portaria do Ministério da Saúde oㅡ 2914 de 2011 (BRASIL, 2011) estabelece os padrões de qualidade da água para o consumo humano, que são fixados com base em risco à saúde humana e, em alguns casos, em características organolépticas da água, conforme orientação da Organização Mundial da Saúde (WHO, 2006).

Para as águas subterrâneas, em escala nacional, foi publicada a Resolução CONAMA no 420 (BRASIL, 2009), que definiu valores orientadores para proteção da qualidade dos solos e águas subterrâneas visando o gerenciamento de áreas contaminadas em todo o território nacional. Esta lista contém valores de investigação, que condizem as concentrações máximas de determinadas substâncias acima das quais existe potencial de risco à saúde humana.

A CETESB, no estado de São Paulo, publicou a Lista de Valores Orientadores para Solos e Águas Subterrâneas (SÃO PAULO, 2005). Esta lista objetiva estabelecer critérios para proteção da qualidade dos solos e águas subterrâneas e indica, para as águas subterrâneas, valores de intervenção, segundo os mesmos princípios dos valores de investigação propostos pela CONAMA no 420 (BRASIL, 2009). Tais valores devem orientar ações de prevenção e controle de contaminação das águas subterrâneas. Além desta, as águas subterrâneas em São Paulo recebem amparo mediante a Lei Estadual no 6.134 de 1988 (SÃO PAULO, 1988), regulamentada pelo Decreto Estadual ํo 32.955 de 1991 (SÃO PAULO, 1991), Lei Estadual oo 7.663 de 1991 (SÃO PAULO, 1991), Decreto Estadual no 41.258 de 1996 (SÃO PAULO, 1996) e as resoluções conjuntas SMA/SERHS ํㅜ 1 de 2005 (SÃO PAULO, 2005) e SMA/SERHS/SES no 3 de 2006 (SÃO PAULO, 2006). Esta última 
inclui procedimentos integrados para controle e vigilância sanitária de águas subterrâneas voltadas ao consumo humano.

No Estado de Minas Gerais, a Lei ㄲo 13.1999 de 1999 dispõe sobre a Política Estadual de Recursos Hídricos (MINAS GERAIS, 1999). Em seu Art. 1 menciona que a Política Estadual de Recursos Hídricos e o Sistema Estadual de Gerenciamento de Recursos Hídricos (SEGRH-MG) devem obedecer esta lei nos termos da Constituição do Estado e na forma da legislação federal. Segundo o Art. 50, constitui infração às normas de utilização de recursos hídricos superficiais ou subterrâneos a ampliação e alteração de empreendimento relacionado com a derivação ou a utilização de recursos hídricos que cause alterações no regime hídrico, quantidade e qualidade, bem como iniciar a sua implantação sem autorização do órgão ou da entidade da administração pública estadual integrante do SEGRH-MG. O Decreto o 41.578 de 2001 regulamente a Lei o 13.199 e dispõe sobre a Política Estadual de Recursos Hídricos (MINAS GERAIS, 2001) e a Lei no 13.771 de 2000 dispõe sobre a administração, a proteção e a conservação das águas subterrâneas de domínio do Estado (MINAS GERAIS, 2000).

O Decreto Estadual № 44.844 de 2008 estabelece normas para licenciamento ambiental e autorização ambiental de funcionamento, tipifica e classifica infrações as normas de proteção aos recursos hídricos e estabelece procedimentos administrativos de fiscalização e aplicação de penalidades (MINAS GERAIS, 2008). Já a Deliberação Normativa CERH-MG oo 26 de 2008 dispõe sobre procedimentos gerais de natureza técnica e administrativa a serem observados no exame de pedidos de outorga para o lançamento de efluentes em corpos de água superficiais no domínio do Estado de Minas Gerais (MINAS GERAIS, 2008). A portaria IGAM № 49 de 2010 estabelece procedimentos para a regularização do uso de recursos hídricos (MINAS GERAIS, 2010a) e a Deliberação Normativa Conjunta COPAM - CERH no 02 de 2010 instituiu o Programa Estadual de Gestão de Áreas Contaminadas (MINAS GERAIS, 2010b).

Em relação ao Estado do Rio de Janeiro, há a Lei no 3.239 de 1999 que instituiu a Política Estadual de Recursos Hídricos, criou o Sistema Estadual de Gerenciamento de Recursos Hídricos, regulamentou a Constituição Estadual (RIO DE JANEIRO, 1999). O Decreto $n^{\circ} \mathbf{4 0 . 1 5 6}$ de 2006 estabelece alguns procedimentos técnicos e administrativos para a regularização dos usos de água superficial e subterrânea (RIO DE JANEIRO, 2006). 
A Lei no 10.179 de 2014 regulamenta a Política Estadual de Recursos Hídricos do Estado do Espírito Santo e institui o Sistema Integrado de Gerenciamento de Recursos Hídricos do Estado (SIGERH/ES) (ESPIRITO SANTO, 2014). A Lei de Águas Subterrâneas do Estado do Espírito Santo - Lei oㅜ 6295 de 2000 - rege sobre a administração, proteção e conservação das águas subterrâneas (ESPIRITO SANTO, 2000). No Estado do Mato Grosso a Lei no 8.907 de 2004 regulamenta sobre a administração e a conservação das águas subterrâneas de domínio do Estado (MATO GROSSO, 2004).

Em relação ao Paraná, a Lei Estadual no 12.726 de 1999 refere-se à Política Estadual de Recursos Hídricos e instituiu o Sistema Estadual de Gerenciamento de Recursos Hídricos (PARANÁ, 1999). Em seu Art. 26, menciona os fundamentos, objetivos, diretrizes gerais de ação e os instrumentos da Política Estadual de Recursos Hídricos. Seu $§ 1^{\circ}$ pauta a preservação e conservação dessas águas, os quais envolvem seu uso racional e medidas que evitem sua contaminação, tanto em relação a aspectos físicos, químicos e biológicos.

No Estado de Santa Catarina há a Lei no 9.748 de 1994, a qual dispõe sobre a Política Estadual de Recursos Hídricos (SANTA CATARINA, 1994), e a Resolução CERH no 02 de 2014, que dispõe sobre o uso das águas subterrâneas no Estado (SANTA CATARINA, 2014).

No Estado do Rio Grande do Sul a Lei oㅜ 10.350 de 1994 instituiu o Sistema Estadual de Recursos Hídricos. Segundo seu Art. 2, a Política Estadual de Recursos Hídricos tem por objetivo promover a harmonização entre os usos múltiplos dos recursos hídricos, considerando sua limitada e aleatória disponibilidade temporal e espacial (RIO GRANDE DO SUL, 1994). O Decreto no 42.047 de 2002 regulamenta a Lei $n^{\circ} 10.350$ e faz alterações referentes ao gerenciamento e à conservação das águas subterrâneas e dos aquíferos no Estado. O Decreto n. 52.035 de 2014 altera o Decreto no 42.047 (RIO GRANDE DO SUL, 2002) com modificações relativas ao gerenciamento e à conservação das águas subterrâneas e dos aquíferos no Estado do Rio Grande do Sul. Segundo seu Art. 25, é "vedada qualquer ação, omissão ou atividade que intencionalmente, ou não, possa causar poluição às águas subterrâneas".

Na Bahia há a Lei oㅜ 11.612 de 2009, que dispõe sobre a Política Estadual de Recursos Hídricos e o Sistema Estadual de Gerenciamento de Recursos Hídricos. Em seu Art. 38 menciona que as águas subterrâneas, em razão de sua importância estratégica, deverão estar sujeitas à programas permanentes de conservação e proteção (BAHIA, 
2009). Em Sergipe a Lei n. 3.870 de 1997 regulamenta a Política Estadual de Recursos Hídricos, cria o Fundo Estadual de Recursos Hídricos e o Sistema Estadual de Gerenciamento de Recursos Hídricos (SERGIPE, 1997). Em Alagoas a Lei o 5.965 de 1997 dispõe sobre a Política Estadual de Recursos Hídricos e instituiu o Sistema Estadual de Gerenciamento Integrado de Recursos Hídricos (ALAGOAS, 1997), enquanto a Lei no 7.094 de 2009 dispõe sobre a conservação e proteção das águas subterrâneas de domínio no estado de alagoas (ALAGOAS, 2009).

Em Pernambuco a Lei o․ 12984 de 1997 refere-se à Política Estadual de Recursos Hídricos e o Sistema Integrado de Gerenciamento de Recursos Hídricos (PERNAMBUCO, 1997a) e a Lei Ordinária n 11.427 de 1997 regulamenta sobre a conservação e a proteção das águas subterrâneas (PERNAMBUCO, 1997b). No Estado da Paraíba há a Lei no 6.308 de 1996, que instituiu a Política Estadual de Recursos Hídricos e suas diretrizes (PARAÍBA, 1996). Já No Estado do Rio Grande do Norte a Lei no 6.908 de 1996 dispõe sobre a Política Estadual de Recursos Hídricos e instituiu o Sistema Integrado de Gestão de Recursos Hídricos - SIGERH" (RIO GRANDE DO NORTE, 1996).

No Estado do Ceará a Lei no 14.844 de 2010 refere-se sobre a Política Estadual de Recursos Hídricos e instituiu o Sistema Integrado de Gestão de Recursos Hídricos SIGERH (CEARÁ, 2010), regulamentada pelo Decreto no 31.077 de 2012, o qual dispõe sobre a política estadual de recursos hídricos no que diz respeito a conservação e a proteção das águas subterrâneas (CEARÁ, 2012). No Piauí a Lei № 5.165 de 2000 regulamenta a Política Estadual de Recursos Hídricos e instituiu o Sistema Estadual de Gerenciamento de Recursos Hídricos (PIAUÍ, 2000). No Estado do Maranhão a Lei ํo. 5.405 de 1992 institui o Código de Proteção de Meio Ambiente e regulamenta o Sistema Estadual de Meio Ambiente e o uso adequado dos recursos naturais do Estado (MARANHÃO, 1992).

No Estado do Pará há a Lei ㄲo 6.381 de 2001, a qual dispõe sobre a Política Estadual de Recursos Hídricos e institui o Sistema Estadual de Gerenciamento de Recursos Hídricos (PARÁ, 2001), e a Lei no 6105 de 1998, a qual regulamenta sobre a conservação e proteção das águas subterrâneas (PARÁ, 1998). No Tocantins a Lei n 1.307 de 2002 refere-se sobre a Política Estadual de Recursos Hídricos (TOCANTINS, 2002). No Acre a Lei o 1.500 de 2003 instituiu a Política Estadual de Recursos Hídricos, criou o Sistema Estadual de Gerenciamento de Recursos Hídricos do Estado do Acre e dispôs sobre infrações e 
penalidades aplicáveis (ACRE, 2003). No Estado de Rondônia a Lei Complementar no 255 de 2002 instituiu a Política Estadual de Recursos Hídricos e criou o Sistema de Gerenciamento e o Fundo de Recursos Hídricos (RONDONIA, 2002). Em Roraima há a Lei Complementar no 007 de 1994, que instituiu o Código de Proteção ao Meio Ambiente para a Administração da Qualidade Ambiental, Proteção, Controle e Desenvolvimento do Meio Ambiente e uso adequado dos Recursos Naturais do Estado de Roraima (RORAIMA, 1994). Já em relação ao Estado do Amapá a Lei no 0686 de 2002 regulamenta a Política de Gerenciamento dos Recursos Hídricos do Estado do Amapá (AMAPÁ, 2002).

Todas as leis e decretos acima descritos têm o objetivo de proteger os recursos hídricos superficiais e subterrâneos de atividades que de algum modo possam causar danos em suas qualidades, devendo ser contempladas, portanto, por atividades mineradoras e industriais. Entretanto, apenas 13 UF legislaram especificamente sobre águas subterrâneas: São Paulo, Minas Gerais, Santa Catarina, Rio Grande do Sul, Distrito Federal, Goiás, Mato Grosso, Mato Grosso do Sul, Alagoas, Pernambuco, Paraíba, Maranhão e Pará. Nas demais UF foram criadas leis, decretos, regulamentos e portarias voltados para as águas superficiais. Assim, grande parte das regiões do país carecem de legislações específicas sobre padrões de qualidade para águas subterrâneas, principalmente considerando diferenças hidrogeoquímicas entre as diferentes áreas.

\section{ASPECTOS TÉCNICOS E DESAFIOS PARA O MONITORAMENTO E TRATAMENTO DA DAM}

Conhecer as características ambientais em áreas de mineração é essencial para um planejamento racional da remediação da poluição. Para uma gestão eficaz e integrada de resíduos sólidos e da DAM, Anawar (2015) sugere a caracterização geológica, geoquímica, mineralógica e microtextural dos depósitos minerais antes das atividades de mineração terem início, além de estudos sobre processos de extração de minério, reações geoquímicas e microbianas, atenuação natural dos poluentes e efeito das mudanças climáticas para reabilitação sustentável das áreas de mineração.

Caraballo et al. (2016) propuseram, com base nas intensas flutuações de carga de metal nas águas subterrâneas, um período de cinco anos de monitoramento contínuo dos efeitos da DAM antes de qualquer sistema de remediação ser projetado em regiões de 
clima mediterrâneo. Os autores sugerem o uso de tratamentos passivos tradicionais para remediar a poluição por DAM nestas áreas, de forma a garantir um monitoramento contínuo da poluição a ser tratada e uma adaptabilidade para abordar de forma eficiente as flutuações de longo prazo.

Gray e Doyle (1994) propuseram protocolos para o controle da contaminação por DAM, após a caracterização dos sítios de mineração, em atividade ou abandonados. Os autores sugerem protocolos para o monitoramento e avaliação das descargas de efluentes ácidos sobre os recursos hídricos para a prevenção de possíveis impactos da DAM sobre as águas receptoras que envolvem: 1) o estabelecimento do critério de qualidade das águas e padrões de lançamento de efluentes; 2) o cálculo da capacidade natural de assimilação dos efluentes ácidos e metais neles contidos; 3) a avaliação do impacto ambiental, incluindo projeções em longo prazo da geração de DAM e dos métodos para remediação, concomitantemente ao desenvolvimento das atividades mineiras; e 4) o próprio estabelecimento do sistema para controle da DAM.

Para o planejamento das atividades de remediação e recuperação ambiental, é importante considerar a identificação dos usuários dos recursos hídricos, o estudo das características das águas naturais e seus efluentes e afluentes, selecionar parâmetros de qualidade para a caracterização dos efeitos da DAM considerando a geoquímica de cada sistema hídrico e definir critérios de qualidade para os recursos hídricos afetados, considerando o suporte legal de cada região, impactos socioeconômicos, políticos e ambientais. Assim, parâmetros de recarga, definição de áreas de recarga e contato com águas superficiais ou outros aquíferos, zonas vulneráveis a contaminação e infiltração de efluentes ácidos, capacidade natural de assimilação dos contaminantes e tamponamento dos efluentes, variações sazonais das características químicas das águas e outros fatores ambientais devem ser estudados de forma criteriosa previamente à adoção de um sistema de tratamento da DAM, atentando-se aos preceitos legais (GRAY e DOYLE, 1994).

As principais normas legais que amparam os recursos hídricos foram descritas, indicando que vários pontos carecem de desenvolvimento com o intuito de proteger eficientemente as águas subterrâneas. Como muitos países ainda não regulamentaram critérios de qualidade para as águas subterrâneas considerando suas diferenças geológicas e químicas e padrões de lançamento de efluentes, inclusive sobre os solos, 
estabelecer critérios para avaliar os impactos da emissão dos efluentes ácidos gerados na mineração sobre os solos e águas subterrâneas torna-se dificultoso.

Desta forma, ainda que existam leis regulamentando os usos das águas subterrâneas e atribuindo orientações para a proteção deste recurso, em particular padrões não foram definidos e, no atual contexto, valores orientadores para a qualidade das águas subterrâneas e dos solos fazem-se urgentes para que o monitoramento ambiental e tratamento de áreas contaminadas por DAM possam ser mais efetivos.

Sabe-se que os problemas concernentes à DAM não serão resolvidos em curto e médio prazo, tampouco por meio de uma intervenção pontual e desarticulada com parâmetros legais e ambientais. Definir critérios de lançamento de efluentes ácidos sobre os solos e águas é essencial também para projetar um sistema de coleta, tratamento e disposição final dos efluentes e resíduos em áreas de mineração que atendam a preceitos básicos de qualidade ambiental. Para tanto, uma avaliação criteriosa sobre os processos ambientais e geoquímicos operantes no meio é essencial durante o planejamento prémineração. $\mathrm{O}$ estudo sobre cargas à montante e jusante dos sistemas aquíferos e possíveis interações com águas superficiais é importante, principalmente em regiões onde tais recursos são utilizados para consumo humano de forma direta. Além disso, considerando a variação do volume e composição da carga de efluentes nas minerações durante processos de operação, o monitoramento contínuo ao longo de anos é necessário para a revisão dos padrões de lançamento de efluentes e de qualidade dos recursos hídricos.

Outros recursos que auxiliam a gestão dos recursos hídricos subsuperficiais e que poderiam ser melhor explorados e desenvolvidos são os mapas de ocorrência e vulnerabilidade dos aquíferos, os quais poderiam delimitar a extensão das atividades de mineração, as áreas de recarga e pontos de contato com outros aquíferos ou corpos d'agua superficiais. Assim, ainda há um campo vasto para investigação dos impactos dos efluentes ácidos gerados em mineração sobre os recursos hídricos subterrâneos, considerando-se o amplo setor mineral brasileiro o que, por sua vez, abrange diferentes formas de processamento mineral, manejo dos recursos naturais e de proteção ambiental, acarretando em formas distintas para o tratamento e remediação de áreas afetadas por DAM.

Embora uma gama de tecnologias seja aplicada no controle e tratamento da DAM, a sustentabilidade de qualquer sistema de remediação é um fator que está se tornando cada 
vez mais crítico, pois muitos processos tradicionais para o tratamento de efluentes geralmente dão origem a novos fluxos de resíduos que requerem tratamento ou eliminação posteriores (SIMATE e NDLOVU, 2014). É fato que os novos processos de tratamento desenvolvidos devem incluir o fator de sustentabilidade. Sem uma compreensão sobre a geração destes novos resíduos de forma que os mesmos possam ser destinados adequadamente ou mesmo aproveitados economicamente, não será alcançada uma gestão eficiente do efluente gerado e do ambiente hídrico que poderá ser impactado.

O uso de resíduos ou subprodutos do tratamento da DAM por outras atividades torna-se um recurso alternativo muito importante. Em um cenário mais adequado, os processos de tratamento poderiam produzir efluentes e resíduos sólidos de qualidade apropriada para serem reciclados e reutilizados em outras aplicações. Como ainda não se concilia de forma satisfatória qualidade ambiental, economia e eficiência energética quando os métodos existentes para tratamento são utilizados individualmente, a integração entre estes e com tecnologias em desenvolvimento (por exemplo, usos de nanomateriais para 0 tratamento de resíduos e efluentes) sobressai como uma alternativa até que seja atingida uma solução com maior potencial para conter os problemas ocasionados por DAM sobre as águas subterrâneas, de forma holística e sustentável.

Desta forma, no atual cenário faz-se necessário maiores investimentos em pesquisas para possibilitar o desenvolvimento de novas tecnologias para tratamento da DAM e separação de metais e outros sub-produtos gerados nos processos de tratamento, como forma de evitar-se a geração de mais efluentes e resíduos a serem depositados sobre a superfície. Técnicas de prevenção da geração da DAM e seu contato com solos e aquíferos devem também ser aprimoradas e adaptadas para cada cenário industrial, ambiental e geológico, sempre em atenção aos preceitos legais e de gestão ambiental.

\section{REFERÊNCIAS}

ACRE. Lei no 1.500, de 15 de julho de 2003. Institui a Política Estadual de Recursos Hídricos, cria o Sistema Estadual de Gerenciamento de Recursos Hídricos do Estado do Acre, dispõe sobre infrações e penalidades aplicáveis e dá outras providências. Rio Branco, 15 de julho de 2003. Disponível em: < http://www.al.ac.leg.br/leis/wp-content/uploads/2014/09/Lei1500.pdf>. Acesso em: 01 mar. 2018.

AKCIL, A. e KOLDAS, S. Acid Mine Drainage (AMD): causes, treatment and case studies. Journal of Cleaner Production, v. 14, p. 1139-1145, 2006. 
ALAGOAS. Li no 5.965, de 10 de novembro de 1997. Dispõe sobre a política estadual de Recursos Hídricos; institui o Sistema Estadual de Gerenciamento Integrado de Recursos Hídricos e dá outras providências. Disponível em: http://www.semarh.al. gov.br/conselhos-ecomissoes/cerh/legislacao-do-cerh/Lei_5965. pdf/view?searchterm=> . Acesso em: 05 de mar. 2018.

ALAGOAS. Lei no 7.094, de 2 de setembro de 2009. Dispõe sobre Conservação e Protecão das águas subterrâneas de Domínio no Estado de Alagoas e dá outras providências. Maceió, 2 de setembro de 2009. Disponível em: <http://agenciapeixevi vo.org.br/wpcontent/uploads/2011/12/images_arquivos_legislacaoambiental_alagoas_Lei_709409_aguasSubterraneas.pdf>. Acesso em: 05 de mar. 2018.

AL-HASHIMI, A.; EVANS, G. J.; COX, B. Aspects of the permanent storage of uranium tailings. Water, Air, and Soil Pollution, v. 88, p. 83-92, 1996.

AMAPÁ. Lei no 0686, de 07 de junho de 2002. Dispõe sobre a Política de Gerenciamento dos Recursos Hídricos do Estado do Amapá e dá outras providências. Macapá, 07 de junho de 2002. Disponível em: < http://www.al.ap.gov.br/ver_texto_lei.php?iddocumento=17698>. Acesso em: 01 mar. 2018.

ANAWAR, H.M. Sustainable rehabilitation of mining waste and acid mine drainage using geochemistry, mine type, mineralogy, texture, ore extraction and climate knowledge. Journal of Environmental Management, v. 158, 2015. p. 111 - 121.

BAHIA. Lei no 11.612, de 08 de outubro de 2009. Dispõe sobre a Política Estadual de Recursos Hídricos, o Sistema Estadual de Gerenciamento de Recursos Hídricos, e dá outras providências. Disponível em: <http://cbhsaofrancisco.org.br/wp-content/uploads/2012 /05/LEI-№-11.612-DE-08DE-OUTUBRO-DE-2009.pdf>. Acesso em: 05 de mar. 2018.

BAIK, M. H.; HYUN, S. P.; HAHN, P. S. Surface and bulk sorption of uranium(VI) onto granite rock. Journal of Radioanalytical and Nuclear Chemistry, v. 256, n. 1, 2003. p. 11-18.

BERGHORN, G. H. e HUNZEKER, G. R. Passive Treatment Alternatives for Remediating Abandoned Mine Drainage. Remediation Journal, v. 11, n. 3, 2001. p. 111- 127.

BRASIL. Decreto n. 97.632: Dispõe sobre a regulamentação do Artigo 2o, inciso VIII, da Lei n. 6.938, de 31 de agosto de 1981, e dá outras providências. 1989.

BRASIL. LEI № 7.805: Lei da Exploração Mineral. 1989. Disponível em: < http://www2.camara.leg.br/legin/fed/lei/1989/lei-7805-18-julho-1989-366155-norma-pl.html>. Acesso em: 25 de fev. de 2017.

BRASIL. Decreto-lei no 227: Dá nova redação ao Decreto-Lei no 1.985 (Código de Minas) de 29 de janeiro de 1940. 1967. Disponível em: < http://www2.camara.leg.br/legin/fed/declei/19601969/decreto-lei-227-28-fevereiro-1967-376017-publicacaooriginal-1-pe.html>. Acesso em: 25 de fev. de 2017.

BRASIL. Lei no 6.938: Política Nacional do Meio Ambiente, seus fins e mecanismos de formulação e aplicação, e dá outras providências. 1981. Disponível em: < http://www2.camara.leg.br/legin/fed/lei/1980-1987/lei-6938-31-agosto-1981-366135normaatualizada-pl.pdf>. Acesso em: 25 de fev. de 2017. 
BRASIL. PORTARIA № 237: Aprova as Normas Reguladoras de Mineração - NRM, de que trata o Art. 97 do Decreto-Lei no227, de 28 de fevereiro de 1967. 2001.

BRASIL. Portaria no 12: Altera a Portaria no 237 de 2001. 2002.

BRASIL. Resolução no 237: Dispõe sobre a revisão e complementação dos procedimen- tos e critérios utilizados para o licenciamento ambiental. 1997a. Disponível em: <

http://www.mma.gov.br/port/conama/legiabre.cfm?codlegi=237>. Acesso em: 25 de fev. de 2017.

BRASIL. Lei n. 9.433: Política Nacional de Recursos Hídricos. Brasília: Secretaria de Recursos Hídricos, 1997b. Disponível em: <http://www.planalto.gov.br/ccivil_03/leis/L9433.htm>. Acesso em: 25 de fev. de 2017.

BRASIL. Conselho Nacional do Meio Ambiente (CONAMA). Resolução n 357/05: Estabelece a classificação das águas doces, salobras e salinas do Território Nacional. Brasília: SEMA, 2005a.

BRASIL. Conselho Nacional do Meio Ambiente (CONAMA). Resolução $\mathbf{n}^{\circ}$ 430/09: Dispões sobre condições e padrões de lançamento de efluentes, completa e altera a Resolução n 357/05.

2005b.

BRASIL. Ministério da Saúde (MS). Portaria no 2914, de 2011: Dispõe sobre os procedimentos de controle e de vigilância da qualidade da água para consumo humano e seu padrão de potabilidade. Brasília: Ministério da Saúde, 2011.

CARABALLO, M.A., Macías, F., Nietoa, J.M., Ayora, C. Science of the Total Environment, v. 539, 2016. p. 427-435.

CEARÁ. Lei no 14.844, de 28 de dezembro de 2010. Dispõe sobre a Política Estadual de Recursos Hídricos, institui o Sistema Integrado de Gestão de Recursos Hídricos - SIGERH, e dá outras providências. Fortaleza, 28 de dezembro de 2010. Disponível em:

$<$ https://www.google.com.br/url?sa=t\&rct=j\&q=\&esrc=s\&source=web\&cd=1\&ved=0ahUKEwijmcrN kOXZAhWJhpAKHdv6BFgQFggoMAA\&url=http\%3A\%2F\%2Fwww.arce.ce.gov.br\%2Findex.php\% 2Flegislacao\%2Fleis\%3Fdownload\%3D171\%253Alei-estadual-14844-de-

281210\&usg=AOvVaw3aYgPIEcxDZXKOrKcA3_9K>. Acesso em: 05 de mar. 2018.

CEARÁ. Decreto no 31.077, 17 de novembro de 2012. Regulamenta a Lei 14.844, de 28 de dezembro de 2010. Diário Oficial do Estado, Fortaleza, 17 de dezembro de 2012. Disponível em: <http://www.mpce.mp.br/wp-content/uploads/2015/12/Decreto-Estadual-no31.077-2012-

Regulamenta-a-Lei-Estadual-no14.844-2010-quanto-à-proteção-das-água-subterrâneas.pdf > . Acesso em: 05 de mar. 2018.

CHEN, T.; YANA, B.; LEI, C.; XIAO, X. Pollution control and metal resource recovery for acid mine drainage. Hydrometallurgy, v. 147-148, 2014. p.112-119.

ESPÍRITO SANTO. Lei no 10.179, de 18 de março de 2014. Dispõe sobre a Política Estadual de Recursos Hídricos, institui o Sistema Integrado de Gerenciamento de Recursos Hídricos do Estado do Espírito Santo - SIGERH/ES e dá outras providências. Diário Oficial da república Federativa do Brasil. Brasília, DF, 18 de março de 2014. Disponível em:

<http://progestao.ana.gov.br/panorama-dos-estados/es/lei-no-10-179-14_es.pdf>. Acesso em: 08 mar. 2018.

ESPÍRITO SANTO. Lei no 6.295, de 25 de março de 2000. Dispõe sobre a administração, proteção e conservação das águas subterrâneas do domínio do Estado e dá outras providências. 
Disponível em: <http://www.al.es.gov.br/antigo_portal_ales/im ages/lei s/html/LO\% 206295.html>. Acesso em: 08 mar. 2018.

FLUES, M; FORNARO, P. H. A. Avaliação da influência da operação da termoelétrica a carvão na concentração dos metais e As no solo de Figueira, PR, Brasil. Química Nova, v. 26, n. 4, 2003. p. 479-483.

FRANCIS, A. J. Microbial dissolution and stabilization of toxic metals and radionuclides in mixed wastes. Experientia, v. 46, 1990. p. 840-851.

FUNGARO, D. A. e IZIDORO, J. C. Remediação da drenagem ácida de mina usando zeólitas sintetizadas a partir de cinzas leves de carvão. Química Nova, v. 29, n. 4, 2006. p. 735-740.

GALHARDI, J.A., BONOTTO, D.M. Geochemistry of Natural Radionuclides Associated with Acid Mine Drainage (AMD) in a Coal Mining Area in Southern Brazil. World Academy of Science, Engineering and Technology, v. 9, 2015. p. 504-511.

GALHARDI, J.A.; BONOTTO, D.M. Hydrogeochemical features of surface water and groundwater contaminated with acid mine drainage (AMD) in coal mining areas. Environmental Science and Pollution Research International, v. 23, 2016. p.18911-18927.

GRAY, N.F., DOYLE, T.M. Characterization of acid mine drainage generating sites. Technical Report: 11, Water Technology Research, Trinity College, University of Dublin, Dublin, 1994. 38 p.

GRAY, N.F. Environmental impact and remediation of acid mine drainage: a management problem. Environmental Geology, v. 30, 1997.

JARVIS, A.P., MOUSTAFA, M., ORME, P.H.A., YOUNGER, P.L. Effective remediation of grossly polluted acidic, and metal-rich, spoil heap drainage using a novel, lowcost, permeable reactive barrier in Northumberland, UK. Environ. Pollut., v. 143, 2006. p. 261-268.

JOHNSON, D. B; HALLBERG, K. B. Acid mine drainage remediation options: a review. Science of the Total Environment, v.338, n. 1, 2055. p. 3- 14.

KIM, J.J., KIM, S.J. Seasonal factors controlling mineral precipitation in the acid mine drainage at Donghae coal mine, Korea. Sci. Total Environ., v. 325, 2004. p. 181-191.

LIMA, H. M.; FLORES, J. C. C.; COSTA, F. L. Plano de recuperação de áreas degradadas versus plano de fechamento de mina: um estudo comparativo. Revista Escola de Minas, v. 59, n. 4, 2006. p. 397-402. Disponível em: < http://www.scielo.br/pdf/rem/v59n4/v59n4a064.pdf >. Acesso em: 2 de abr. de 2017.

MARANHÃO. Lei no 5.405, de 08 de abril de 1992. Institui o Código de Proteção de Meio Ambiente e dispõe sobre o Sistema Estadual de Meio Ambiente e o uso adequado dos recursos naturais do Estado do Maranhão. Disponível em:

<http://www.caema.ma.gov.br/portalcaema/index.php?option=com_docman\&task=doc_details\&gid $=150 \&$ Itemid=61>. Acesso em: 05 de mar. 2018.

MATO GROSSO. Lei no $\mathbf{8 . 9 0 7}$, de 24 de março de 2004. Dispõe sobre a administração e a conservação das águas subterrâneas de domínio do Estado e dá outras providências. Cuiabá, 24 de março de 2004. Disponível em: <http://rouxinol.mt.gov .br/Aplicativos/Sad-

Legislacao/LegislacaoSad.nsf/709f9c981a9d9f468425671300

482be0/b22c367bcc3615b604256e9f00558c85?OpenDocument>. Acesso em: 05 de mar. 2018. 
MELLO, J. W. V.; DUARTE, H. A.; LADEIRA, A. C. Q. Origem e Controle do Fenômeno Drenagem Ácida de Mina. Cadernos Temáticos de Química Nova na Escola, n. 8, 2014. p. 24-29. Disponível em: < http://qnesc.sbq.org.br/online/cadernos/08/06-CTN4.pdf>. Acesso em: $10 \mathrm{de}$ mar. 2017.

MINAS GERAIS. Lei no 13.199, de 29 de janeiro de 1999. Dispõe sobre a Política Estadual de Recursos Hídricos e dá outras providências. Diário Oficial da república Federativa do Brasil. Brasília, DF, 30 de janeiro de 1999. Disponível em: <http://www.siam.mg.gov.br/sla /download.pdf?idNorma=5309>. Acesso em: 08 mar. 2018.

MINAS GERAIS. Decreto no 41.578, de 08 de março de 2001. Regulamenta a Lei no 13.199, de 29 de janeiro de 1999, que dispõe sobre Política Estadual de Recursos Hídricos. Diário do Executivo, Brasília, DF, 08 mar. 2001.

MINAS GERAIS. Lei no13.771, de 11 de dezembro de 2000. Dispõe sobre a administração, a proteção e a conservação das águas subterrâneas de domínio do Estado e dá outras providências. Diário Oficial da república Federativa do Brasil. Brasília, DF 12 de dezembro de 2000. Disponível em: <http://www.siam.mg.gov.br/sla/download.pdf?idNorma=549>. Acesso em: 08 mar. 2018.

MINAS GERAIS. Decreto no 44.844, de 25 de junho de 2008. Estabelece normas para licenciamento ambiental e autorização ambiental de funcionamento, tipifica e classifica infrações às normas de proteção ao meio ambiente e aos recursos hídricos e estabelece procedimentos administrativos de fiscalização e aplicação das penalidades. Diário do Executivo, Minas Gerais, MG, 26 jun. 2008.

MINAS GERAIS. Portaria no 49, de 01 de julho de 2010. Estabelece os procedimentos para a regularização do uso de recursos hídricos do domínio do Estado de Minas Gerais. Diário do Executivo, Minas Gerais, MG, 06 jul. 2010.

NORDSTROM, D.K., ALPERS, C.H., PTACEK, C.J., BLOWES, D.W. Negative pH and extremely acidic mine water from Iron Mountain, California. Environ. Sci. Technol., v. 34, 2000. p. 254258.

PAIKARAY, S. Arsenic Geochemistry of Acid Mine Drainage. Mine Water Environ, v. 34, 2015. p. 181-196.

PARÁ. Lei no 6105, de 14 de janeiro de 1998. Dispõe sobre a conservação e proteção dos depósitos de águas subterrâneas no Estado do Pará e dá outras providências. Palácio Do Governo, 14 de janeiro de 1998. Disponível em: < https://www.semas. pa.gov.br/1998/01/14/9750/>. Acesso em: 01 mar. 2018.

PARÁ. Lei no 6381, de 25 de julho de 2001. Dispõe Sobre a Política Estadual de Recursos Hídricos, instituí o Sistema de Gerenciamento de Recursos Hídricos e dá outras providências. PALÁCIO DO GOVERNO, 25 de julho de 2001. Disponível em: < https://www.semas.pa.gov.br/2001/07/25/9760/>. Acesso em: 01 mar. 2018.

PARAÍBA. Lei no 6.308, de 02 de julho de 1996. Institui a Política Estadual de Recursos Hídricos, suas diretrizes e dá outras providências. João Pessoa, em 02 de julho de 1996. Disponível em: <http://www.aesa.pb.gov.br/aesa-website/wp-content/uploads/2016/11/lei_E_11.pdf>. Acesso em: 05 de mar. 2018. 
PARANÁ. Lei no12.726, de 26 de novembro de 1999. Institui a Política Estadual de Recursos Hídricos e adota outras providências. Diário Oficial da república Federativa do Brasil. Brasília, DF, 29 de novembro de 1999. Disponível em:

$<$ http://www.legislacao.pr.gov.br/legislacao/listarAtosAno.do?action=exibir\&codAto=5849\&codltem Ato $=40340>$. Acesso em: 08 mar. 2018.

PERNAMBUCO (a). Lei no 12.984, de 30 de dezembro de 2005. Dispõe sobre a Política Estadual de Recursos Hídricos e o Sistema Integrado de Gerenciamento de Recursos Hídricos, e dá outras providências. Palácio do Campo das Princesas, em 30 de dezembro de 2005. Disponível em: $<$ http://www.apac.pe.gov.br/legislacao/lei_das

aguas_n_12984_de_30_de_dezembro_de_2005.pdf >. Acesso em: 05 de mar. 2018.

PERNAMBUCO (b). Lei no 11.427, de 17 de janeiro de 1997. Dispõe sobre a conservação e a proteção das águas subterrâneas no Estado de Pernambuco e dá outras providências. Palácio do Campo das Princesas, em 17 de janeiro de 1997. Disponível

em:<http://legis.alepe.pe.gov.br/texto.asp?tiponorma=1\&numero=11427\&complemento=0\&ano=19 97\&tipo=\&url=>. Acesso em: 05 de mar. 2018.

PIAUÍ. Lei no 5.165, 17 de agosto de 2000. Dispõe sobre Política Estadual de Recursos Hídricos, institui o sistema estadual de gerenciamento de recursos hídricos. Disponível em:

$<$ http://seirh.semas.pa.gov.br/index.php/biblioteca/109-pi-lei5165-2000-2.html?path=>. Acesso em: 05 de mar. 2018.

RIO DE JANEIRO. Lei no 3239, de 2 de agosto de 1999. Dispõe sobre a Política Estadual de Recursos Hídricos e dá outras providências. Diário Oficial da república Federativa do Brasil. Brasília, DF, 02 de agosto de 1999. Disponível em: http://alerjln1.alerj.rj.gov.br/CONTLEI.NSF/b24a2da5a077847c032564f400 5d4bf2/43fd110fc03f0e6c032567c30072625b. Acesso em: 08 mar. 2018.

RIO DE JANEIRO. Decreto no 40.156, de 17 de outubro de 2006. Estabelece os procedimentos técnicos e administrativos para a regularização dos usos de água superficial e subterrânea, bem como, para ação integrada de fiscalização com os prestadores de serviço de saneamento básico, e dá outras providências. Rio de Janeiro, 17 de outubro de 2006. Disponível em:

$<$ http://www.inea.rj.gov.br/cs/groups/public/documents/document/zwff/mde1/ edisp/inea_015258.p df>. Acesso em: 05 de mar. 2018.

RIO GRANDE DO NORTE. Lei no 6.908, de 01 de julho de 1996. Dispõe sobre a Política Estadual de Recursos Hídricos, institui o Sistema Integrado de Gestão de Recursos Hídricos - SIGERH e dá outras providências. Natal, 01 de julho de 1996. Disponível eM:

<http://adcon.rn.gov.br/ACERVO/semarh/DOC/DOC0000000000 17407.PDF>. Acesso em: 05 de mar. 2018.

RIO GRANDE DO SUL. Lei no 10.350, de 30 de dezembro de 1994. Institui o Sistema Estadual de Recursos Hídricos, regulamentando o artigo 171 da Constituição do Estado do Rio Grande do Sul. Diário Oficial da república Federativa do Brasil. Brasília, DF, 01 jan. 1995. Disponível em: <http://www.charqueadas.rs.gov.br/vigilancia/vig_amb/vig iagua/Lei\%2010350.pdf>. Acesso em: 08 mar. 2018.

RIO GRANDE DO SUL. Decreto no 52.035, de 19 de novembro de 2014. Altera o Decreto no 42.047 de 26 de dezembro de 2002, que regulamenta as disposições da Lei no 10.350, de 30 de dezembro de 1994, com alterações, relativas ao gerenciamento e à conservação das águas subterrâneas e dos aquíferos no Estado do Rio Grande do Sul. 
RONDONIA. Lei Complementar n을 255, de 25 de janeiro de 2002. Institui a Política, cria o Sistema de Gerenciamento e o Fundo de Recursos Hídricos do Estado de Rondônia e dá outras providências. Palácio do Governo do Estado de Rondônia, em 25 de janeiro de 2002. Disponível em: < http://progestao.ana.gov.br/panorama-dos-estados/ro/lei-no-255-02_ro.pdf>. Acesso em: 01 mar. 2018.

RORAIMA. Lei Complementar no 007, de 26 de agosto de 1994. Institui o Código de Proteção ao Meio Ambiente para a Administração da Qualidade Ambiental, Proteção, Controle e Desenvolvimento do Meio Ambiente e uso adequado dos Recursos Naturais do Estado de Roraima. Disponível em: <http://www.tjrr.jus.br/legislacao/phocadown load/LeisComplementaresEstaduais/1992_1999/LEI_COMPLEMENTAR_N_007_DE_26_DE_AG OSTO_DE_1994.pdf>. Acesso em: 01 mar. 2018.

SÃO PAULO. Lei no 7.663: Estabelece normas de orientação à Política Estadual de Recursos Hídricos bem como ao Sistema Integrado de Gerenciamento de Recursos Hídricos. 1991. Disponível em: < http://www.al.sp.gov.br/repositorio/legislacao/lei/1991/lei-7663-30.12.1991.html>. Acesso em: 18 de mai. de 2017.

SÃO PAULO. Decreto no 41.258: Aprova o regulamento dos artigos 9 a 13 da Lei n 7.663 de 30 de dezembro de 1991. 1996. Disponível em: < http://www.daee.sp.gov.br/legislacao/arquivos/799/DECRETO_412581996.pdf>. Acesso em: 18 de mai. de 2017.

SÃO PAULO. Resolução Conjunta SMA/SERHS no 1: Regula o Procedimento para o Licenciamento Ambiental Integrado às Outorgas de Recursos Hídricos. 2005. Disponível em: < http://www.daee.sp.gov.br/legislacao/arquivos/1462/resolucaosma1.pdf>. Acesso em: 18 de mai. de 2017.

SÃO PAULO. Resolução Conjunta SMA/SERHS/SES - 3: dispõe sobre procedimentos integrados para controle e vigilância de soluções alternativas coletivas de abastecimento de água para consumo humano proveniente de mananciais subterrâneos. 2006. Disponível em: < http://www.cetesb.sp.gov.br/licenciamento/documentos/2006_Res_Conj_SMA_SERHS_SES_03.p df>. Acesso em: 18 de mai. de 2017.

\section{SÃO PAULO. Relatório de Qualidade de Águas Interiores no Estado de São Paulo 2005.}

Disponível em: < http://aguasinteriores.cetesb.sp.gov.br/publicacoes-e-relatorios/>. Acesso em: 18 de mai. de 2017.

SANTA CATARINA. Lei no 9.748, de 30 de novembro de 1994. Dispõe sobre a Política Estadual de Recursos Hídricos e dá outras providências. Florianópolis, 30 de novembro de 1994.

Disponível em: <http://www.aguas.sc.gov.br/jsmallfib_top/DHRI/Legislacao/Lei-Estadual-97481994.pdf>. Acesso em: 25 de fev. de 2017.

SERGIPE. Lei no 3.870, de 25 de setembro de 1997. Dispõe sobre a Política Estadual de Recursos Hídricos e o Sistema Estadual de Gerenciamento de Recursos Hídricos e dá outras providencias. Aracaju, 25 de setembro de 1997. Disponível em:

<http://agenciapeixevivo.org.br/wp-content/uploads/2011/12/images_arquivos_legislac aoambiental_sergipe_lei_n_3870.pdf>. Acesso em: 05 de mar. 2018.

SILVA, L. F. O.; WOLLENSCHLAGER, M.; OLIVEIRA, M. L. S. A preliminary study of coal mining drainage and environmental health in the Santa Catarina region, Brazil. Environ. Geochem.

Health, v. 33, 2011. p. 55-65. 
SILVA, L.F.O.; VALLEJUELO, S.F.O.; MARTINEZ-ARKARAZO. I.; CASTRO, K.; OLIVEIRA, M.L.S.; SAMPAIO, C.H.; BRUM, I.A.S.; LEÃO, F.B.; TAFFAREL, S.R.; MADARIAGA, J.M. Study of environmental pollution and mineralogical characterization of sediment rivers from Brazilian coal mining acid drainage. Science of the Total Environment, v. 447, 2013. p. 169-178.

SIMATE, G.F.; NDLOVU, S. Acid mine drainage: Challenges and opportunities. Journal of Environmental Chemical Engineering 2, 2014. p. 1785-1803.

SIMONA, R.; ANDREAS, B.; STEFAN, P. Formation and stability of schwertmannite in acidic mining lakes. Geochim Cosmochim Acta, v. 68, 2004. p. 1185-97.

SOLDERA, B. C. Água sustentável: definição de um novo indicador ambiental. 2017. $139 f$. Tese (Doutorado em Geociências e Meio Ambiente) - Universidade Estadual Paulista "Júlio de Mesquita Filho" - IGCE. Rio Claro. 2017.

TOCANTINS. Lei no 1.307, de 22 de março de 2002. Dispõe sobre a Política Estadual de Recursos Hídricos, e adota outras providências. Palmas, 22 de março de 2002. Disponível em: < http://mpto.mp.br/intranet/caopma/leg_est/LEl\%201.307,\%20DE\%2022\%20DE\%20MARÇO \%20DE\%202002.pdf>. Acesso em: 01 mar. 2018.

UNITED STATES ENVIRONMENTAL PROTECTION AGENCY (USEPA). Office of Solid Waste. Human health and environmental damages from mining and mineral processing wastes. 1995. Disponível em: < http://www.epa.gov >. Acesso em 15 de fevereiro de 2015.

WORLD HEALTH ORGANIZATION (WHO). Guidelines for drinking-water quality: first addendun to third edition - Recommendations, v. 1. 3 ed. Geneve: WHO, 2006. 515 p. Disponível em: < http://www.who.int/water_sanitation_health/dwq/gdwq0506.pdf >. Acesso em: 05 de fevereiro de 2015.

YOUNGER, P.L. The longevity of mine water pollution: a basis for decision-making. Sci.Total Environ, v.194-195, 1997. p. 457-466.

YOUNGER, P.L. Predicting temporal changes in total iron concentrations in groundwater flowing from abandoned deep mines: a first approximation. J. Contam. Hydrol. v. 44, n. 1, 2004. p. 4769. 